\title{
Effect of ambient temperature storage on 2,2-diphenyl-1-picrylhydrazyl (DPPH) as a free radical for the evaluation of antioxidant activity
}

\author{
David A. OTOHINOYI ${ }^{1}$, Okobi EKPO ${ }^{2}$ and Omodele IBRAHEEM ${ }^{1 *}$ \\ ${ }^{1}$ Department of Biological Sciences, Landmark University, Omu-Aran, PMB 1001, Kwara State, Nigeria. \\ ${ }^{2}$ Department of Medical Biosciences, University of the Western Cape, Private Bag X17, \\ Bellville 7535, South Africa. \\ *Corresponding author; E-mail: deleibraheem2007@yahoo.com
}

\begin{abstract}
Antioxidants are molecules involved in defense mechanisms against the deleterious effects of free radicals in most organisms. A number of methods are currently being used for the evaluation of the antioxidant and free-radical scavenging properties of natural and synthetic antioxidants, including the DPPH method. Numerous speculations about the stability of DPPH solution over a long period of time, at normal ambient temperature have been observed in previous studies but no definite information exists in literature in this regard. Using established protocols, the free-radical capability of DPPH methanolic solution (stored in dark at ambient temperature) was assessed using ascorbic acid as the antioxidant. Results revealed that DPPH methanolic solution gave comparable free-radical activity 24 hours post preparation compared with the freshly prepared solution. After 24 hours, activity was greatly reduced. We therefore recommend that freshly prepared DPPH solution should be used at all times; however for prolonged experimental schedules, the DPPH solution should be used within 24 hours post preparation, so as to give comparable results with the freshly prepared solution and avoid ambiguity in results interpretation.

(c) 2014 International Formulae Group. All rights reserved.
\end{abstract}

Keywords: Ascorbic acid, methanolic, oxygen species, phytochemicals, stability.

\section{INTRODUCTION}

The harmful effects of free radicals of reactive oxygen species (such as $\mathrm{OH}^{\circ}, \mathrm{O}_{2}{ }^{--}$, $\mathrm{NO}^{-}$and $\mathrm{H}_{2} \mathrm{O}_{2}$ ) to human health have been highlighted in the pathogenesis of many diseases and conditions including cancer, Alzheimer's disease, diabetes, Parkinson's disease, cardiovascular diseases, rapid ageing as well as many immune-compromised diseases (Rahman, 2007). This has brought increasing interest in the study of antioxidant drugs (such as butylhydroxytoluene, butylhydroxyanisole, quercetin rutinoside, gallates, etc.), and more importantly the naturally occurring phytochemicals such as alkaloids, phenolic acids, flavonoids, saponins, anthrocyanins, tannins, terpenoids, etc. as well as vitamins with potent antioxidant and free radical scavenging properties such as vitamin $\mathrm{C}$, vitamin $\mathrm{E}, \beta$ carotene and vitamin E (Fang et al., 2002; Gulcin, 2012).

Although endogenous enzymes such as catalase, superoxide dismutase, glutathione 
peroxidase etc., are often involved in scavenging free radicals (Chance et al., 1979), they often cannot provide complete protection to the cells against the deleterious effects of these reactive oxygen species, hence the need for exogenously supplied antioxidants which are derived from natural or synthetic sources.

Among the many assays for determining antioxidant and free radical scavenging properties is the well-known 2,2 diphenyl 1picrylhydrazyl (DPPH) assay, also known as the 1,1-Diphenyl-2-picrylhydrazyl assay (Molyneux, 2004; Pisoschi, 2011). DPPH is usually a dark-coloured, powdered organic compound composed of stable free-radical molecules with many crystalline forms (Kiers et al., 1976; Teruaki, 1981). The commercial DPPH powder has a melting point of approximately $130{ }^{\circ} \mathrm{C}$ (Kiers et al., 1976). Besides its free radical properties, DPPH has been used for the determination of the position and intensity of electron paramagnetic resonance signals, and its activity was shown to be concentration-dependent and to follow Beer Lambert's law (Kiers et al., 1976; Teruaki, 1981; Meléndez et al., 2014).

As it is the case with other free radical compounds which could dimerise, DPPH forms a stable free compound, mainly due to the delocalization of the free electron on the whole compound, which forms a deep violet colour in ethanol and gives maximum absorbance at about $520 \mathrm{~nm}$ (Thaipong et al., 2006; Sharma and Bhat, 2009). The deep violet colour however becomes colourless or pale yellow after reacting with a hydrogen donor (Figure 1), thus the free radical potential of DPPH can be easily monitored spectrophotometrically at optical absorption of $520 \mathrm{~nm}$. Consequently, a decrease in absorbance at $520 \mathrm{~nm}$ is a direct linear relationship to the free radical ability of DPPH.
Blois (1958) showed that when DPPH radical $\left(Z^{*}\right)$ was reduced by hydrogen donated from the cysteine molecule $(\mathrm{RSH}) ; \mathrm{Z}^{*}+\mathrm{RSH}$ $=\mathrm{ZH}+\mathrm{RS}^{*}$, the free radical $\mathrm{RS}^{*}$ reacted with an identical molecule to form a disulphide; $\mathrm{RS}^{*}+\mathrm{RS}^{*}=\mathrm{RS}-\mathrm{SR}$. Thus two molecules of DPPH react with two free $\mathrm{RS}^{*}$ to give a stoichiometry of $1: 1$.

However, in the case of ascorbic acid that has two adjacent sites for hydrogen abstraction, 2 molecules of DPPH will reduce 1 molecule of ascorbic acid, giving a stoichiometry of 2:1, as illustrated below:

$\mathrm{Z}^{*}+\mathrm{R}-\mathrm{COH}=\mathrm{COH}-\mathrm{R}^{\prime} \rightarrow \mathrm{ZH}+\mathrm{R}-\mathrm{COH}=\mathrm{CO}^{*}-\mathrm{R}^{\prime}--(1)$

$\mathrm{Z}^{*}+\mathrm{R}-\mathrm{COH}=\mathrm{CO} *-\mathrm{R}^{\prime} \rightarrow \mathrm{ZH}+\mathrm{R}-\mathrm{CO}-\mathrm{CO}-\mathrm{R}^{\prime}--(2)$

Although powdered DPPH stored at cold temperature in a dark bottle is generally believed to be stable, its stability in solution (in ethanol, methanol, etc.) has not, however, been fully established (Lin, 2012). It is usually advised that fresh DPPH solution must be prepared at all times. However, during an experiment that may require prolonged assays which could expose the solution to ambient temperature or worse to higher temperature, how stable will the solution be, and how authentic will the ensuing result be? Many researchers wrap DPPH solutions with aluminum foil to mimic a dark environment; however, the solutions may become exposed to light by error, even for prolonged periods, with the possibility that the DPPH solution may adapt to the illuminated environment.

Based on this information, we therefore carried out this study in order to determine the stability of DPPH solution stored in the dark at ambient temperature of about $23{ }^{\circ} \mathrm{C}-27$ ${ }^{\circ} \mathrm{C}$, for a period of 240 hours. The ability of the DPPH to act as a free radical, inspite of this treatment, was evaluated using ascorbic acid. 


\section{MATERIALS AND METHODS}

Methanol (analytical standard), DPPH and L-Ascorbic Acid powder (cell tested $\gamma$-irradiated) were all purchased from Sigma-Aldrich Chemie GMBH. The free radical activity of freshly prepared DPPH stored in dark bottle was assayed according to the method of Brand-Williams et al. (1995) using methanol as solvent. This solution was allowed to stand in dark at ambient temperature $\left(23^{\circ} \mathrm{C}-27^{\circ} \mathrm{C}\right)$ and aliquots taken at intervals (after 24, 48, 120 and 240 hours; post preparation) were also assayed for their residual free radical activity using the same method.

The percent antioxidant activities (AA\%) of three concentrations of ascorbic acids $(10,50,100 \mathrm{mg} / \mathrm{ml}$; prepared in methanol) were used to evaluate the free radical activity of the DPPH samples. To $1 \mathrm{ml}$ of each ascorbic acid concentration, $3 \mathrm{ml}$ of $0.1 \mathrm{mM}$ DPPH methanolic solution was added; reaction mixtures were allowed to stand for 30 minutes in the dark. Change in the color from deep violet to pale yellow was read at an absorbance of $517 \mathrm{~nm}$ using $\mathrm{DU}^{\circledR} 800 \quad$ UV/VIS Spectrophotometer,

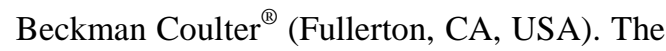
blank consisted of pure methanol solvent without ascorbic acid or DPPH, while the control was made of $0.1 \mathrm{mM}$ DPPH methanolic solution without ascorbic acid. The antioxidant activity was determined according to Mensor et al. (2001) as shown below.

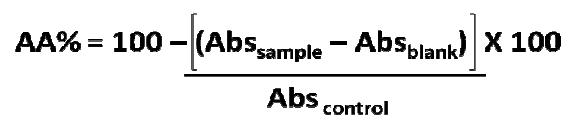

The experiment was carried out in triplicates for the three ascorbic acid concentrations. Results obtained were expressed as percentage decrease with respect to DPPH control results. The means of the triplicate results and standard deviation were determined. Statistical analyses were performed by one-way analysis of variance (ANOVA). The coefficient of variation of the sample from the control was considered statistically significant at $\mathrm{p} \leq 0.05$.

\section{RESULTS}

Results obtained from ascorbic acid neutralization of freshly prepared DPPH solution were compared with ascorbic acid neutralization with DPPH solutions after 24, 48, 120 and 240 hours post preparation respectively, stored at ambient temperature in dark (Figure 2). Our findings showed that at 24 hours post preparation, the free radical activity of $0.1 \mathrm{mM}$ DPPH methanolic solution was still very similar to that of the fresh preparation, as evaluated using ascorbic acid as the antioxidant. However about 20\% activity was lost after about 120 hours, and over $80 \%$ after 240 hours post preparation.

Furthermore, the stability of the untreated DPPH methanolic solution as adjudged by its absorbance at $517 \mathrm{~nm}$, showed that the solution was still comparable with the freshly prepared solution up to 24 hours, with gradual decrease in absorbance over time (Figure 3). Although the absorbance reading at 240 hours post preparation appears to be close to the reading for the fresh preparation, it should however be noted that this does not translate into its free radical activity as evaluated using ascorbic acid as the antioxidant, shown in Figure 2, where over $80 \%$ of the activity was lost during this period. Thus, having a remarkable absorbance reading does not necessarily infer that the DPPH solution is still active. 


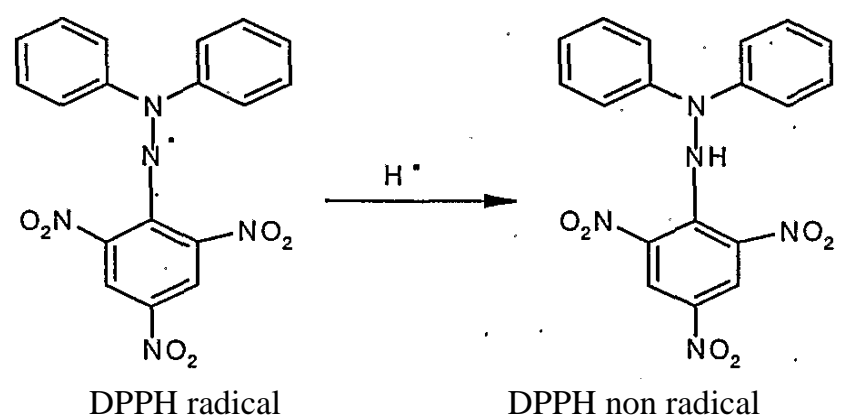

Figure 1: Neutralization reaction of DPPH with a free hydrogen $\left(\mathrm{H}^{*}\right)$ donor.

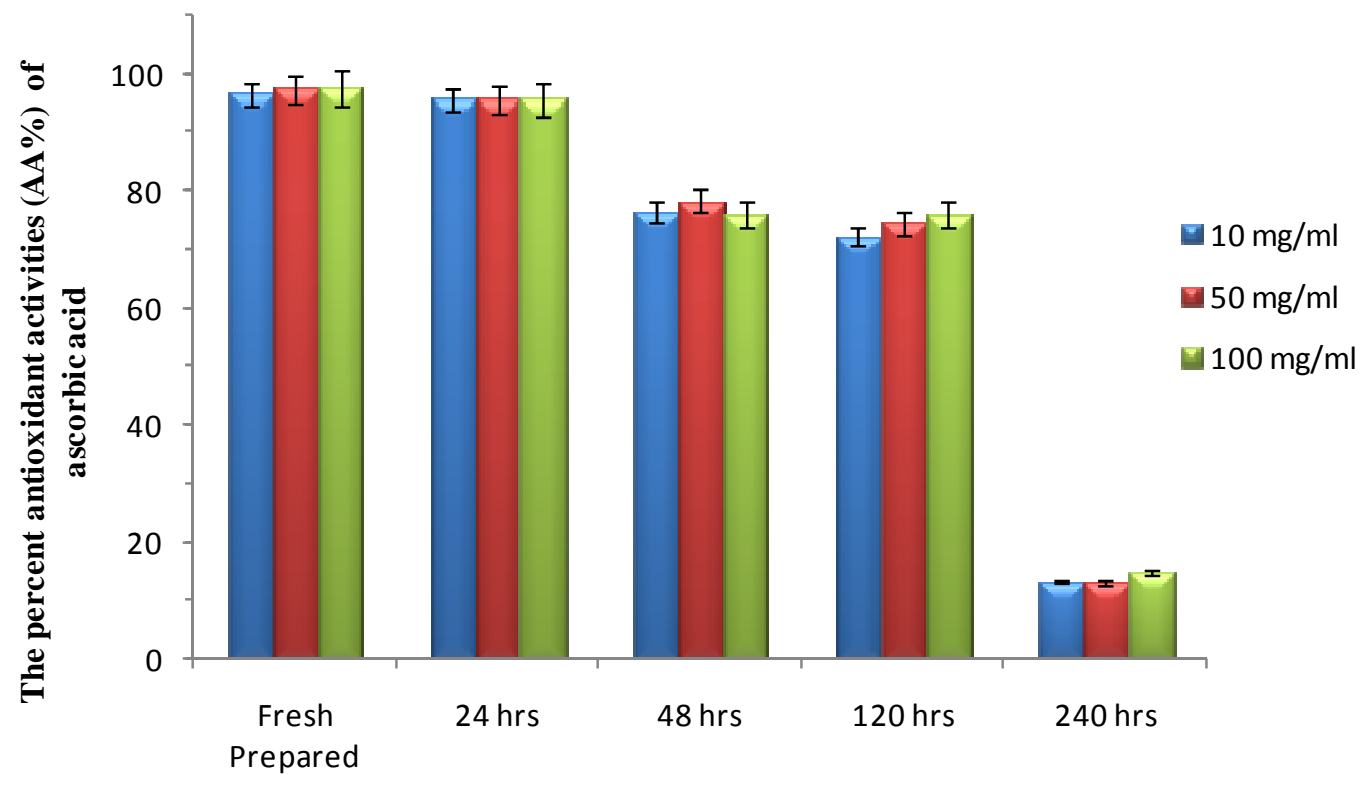

Period of storage of $0.1 \mathrm{mM}$ DPPH methanolic solution at ambient temperature in dark

Figure 2: The percent antioxidant activities (AA \%) of ascorbic acid at different concentrations (10, $50,100 \mathrm{mg} / \mathrm{ml}$ ) used in evaluating the free radical activity of $0.1 \mathrm{mM}$ DPPH methanolic solution. Aliquots from freshly prepared, as well as 24, 48, 120 and 240 hours post preparation stored at ambient temperature in the dark were assayed according to the method of Brand-Williams et al., (1995). The experiment was performed in triplicates. Values were the average of means, and represented as mean \pm standard deviation. Statistical analyses were performed by one-way analysis of variance (ANOVA). Coefficient of variation of the DPPH-ascorbic acid sample from DPPH control was considered statistically significant at $\mathrm{p} \leq 0.05$. 


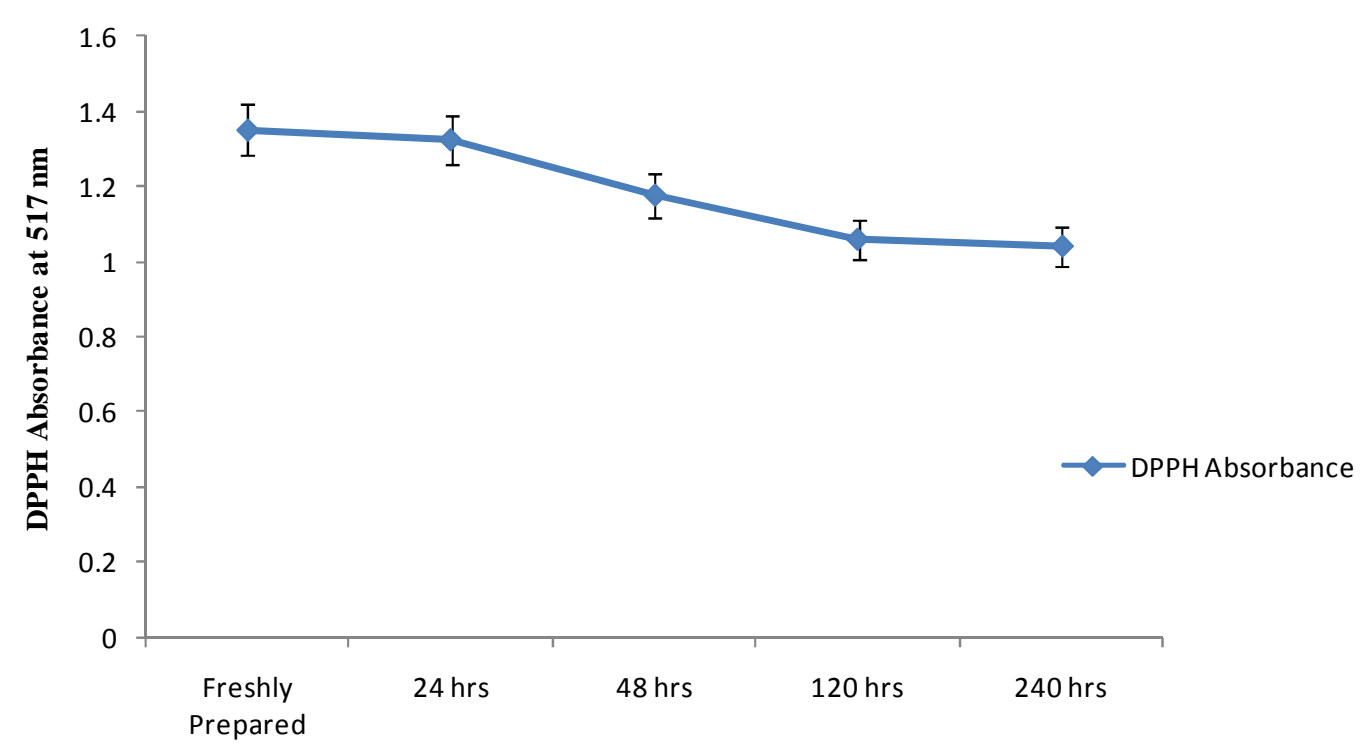

Period of storage of $0.1 \mathrm{mM}$ DPPH methanolic solution at ambient temperature in dark

Figure 3: The $517 \mathrm{~nm}$ absorbance reading of $0.1 \mathrm{mM}$ DPPH methanolic solution stored at ambient $\left(23{ }^{\circ} \mathrm{C}-27^{\circ} \mathrm{C}\right)$ and aliquots taken at $24,48,120$ and $240 \mathrm{hrs}$ post preparation. The experiment was done in triplicates. Values were the average of means, and represented as mean \pm standard deviation.

\section{DISCUSSION}

This experiment should put to rest the controversies on the stability of the free radical activity of DPPH solution (Lin 2012), which currently no validated / published information exist as regards. This experiment has shown that DPPH methanolic solution when used within 24 hours post preparation and stored in the dark should give appreciable results like a freshly prepared stock. Although the use of regression analysis to ascertain the concentration of residual DPPH post preparation has been proposed (Marxen et al., 2007), this may give contradictory results, as results may not be comparable with the freshly prepared solution. It is therefore advisable to stick to the limit by which the DPPH solution may seem effective. Although DPPH absorbance value was adjudged to be related to its concentration (Marxen et al., 2007), Figures 2 and 3 have clearly shown that DPPH activity and absorbance value after a long storage period are mutually exclusive, irrespective of the concentration.

Use of $0.05 \mathrm{mM}-0.1 \mathrm{mM}$ DPPH in solvents (such as methanol / ethanol / water) has been shown to absorb strongly at visible region between $515 \mathrm{~nm}$ to $520 \mathrm{~nm}$ (Molyneux, 2004, Fernandez-Orozco et al., 2011) when used at a maximum working volume of $4 \mathrm{ml}$; however, in our unpublished preliminary experimental work using DU®800 UV/VIS Spectrophotometer, (Beckman Coulter® Fullerton, CA, USA), $0.1 \mathrm{mM}$ DPPH methanolic solution showed highest absorbance at $517 \mathrm{~nm}$, hence this wavelength was used in this study.

Furthermore, the use of high ascorbic acid concentrations $(10,50,100 \mathrm{mg} / \mathrm{ml})$ for this experiment was to ensure that the maximum potential of DPPH as a free radical compound was attained. Although ascorbic acid concentrations as low as $10-300 \mu \mathrm{g} / \mathrm{ml}$ have been used in previous studies (Sahaa et 
al., 2008; Abalaka et al., 2011), using these low concentrations could still have given appreciable results, even when the free radical activity of DPPH has been greatly reduced. Hence if DPPH free radical activity could be active at $100 \mathrm{mg}$ ascorbic acid concentration, it could then be said that at lower concentrations, its activity will even be more evident. Ascorbic acid concentration as high as $100 \mathrm{mg} / \mathrm{ml}$ was recently used by Gracia et al. (2012) as a potential solution to be applied on bleached teeth.

It should be noted that we did not investigate the effect of water on the DPPH free radical activity, as some assays (Prior, et al., 2005; Stasko, 2007) involved 0 - 50\% ethanol /methanol (v/v), therefore what could have been observed in the DPPH $0-50 \%$ organic solvent solution, may or may not be comparable with results obtained in this experiment.

In Meléndez et al. (2014), it was stated that Molyneux (2004) reported DPPH solution was stable for 3 days. However, this seems not in Molyneux (2004) report. We therefore recommend that all efforts should be made to use freshly prepared DPPH solution. However, if there is a need to re-use DPPH or a freshly prepared solution is allowed to stand for long because of a prolonged experimental procedure, then the DPPH solution must be stored in a dark bottle at ambient $\left(23{ }^{\circ} \mathrm{C}-27\right.$ ${ }^{\circ} \mathrm{C}$ ) temperature, and must be used up 24 hours post preparation. This will ensure that unambiguous and credible results comparable with the freshly prepared solution are obtained.

\section{ACKNOWLEDGMENTS}

The authors are grateful for financial assistance and laboratory spaces provided by Landmark University, Nigeria and the University of the Western Cape, South Africa.

\section{REFERENCES}

Abalaka ME, Mann A, Adeyemo SO. 2011. Studies on in-vitro antioxidant and free radical scavenging potential and phytochemical screening of leaves of Ziziphus mauritiana L. and Ziziphus spinachristi L. compared with Ascorbic acid. J. Med Genetics \& Genomics, 3(2): $28-34$.

Blois MS. 1958. Antioxidant Determinations by the Use of a Stable Free Radical. Nature, 181: 1199 - 1200.

Brand-Williams W, Cuvelier ME, Berset C. 1995. Use of a free radical method to evaluate antioxidant activity. Lebenson Wiss Technol., 28: 25-30.

Chance PA, Sies H, Boveris A. 1979. A hydroperoxide metabolism in mammalian organs. Physiol. Rev., 59: 527-605.

Fang YZ, Yang S, Wu G. 2002. Free radicals, antioxidants, and nutrition. Nutrition, $\mathbf{1 8}$ : 872-879.

Fernandez-Orozco R, Roca M, Gandul-Rojas B, Gallardo-Guerrero L. 2011. DPPHscavening of chloroplastic pigments and phenolic compounds of olive fruits (cv. Arbequina) during ripening. J. Food Compos. Anal., 24: 858-864.

Garcia EJ, Oldoni TLC, de Alencar SM, Reis A, Loguercio AD, Grande RHM. 2012. Antioxidant Activity by DPPH Assay of Potential Solutions to be Applied on Bleached Teeth. Braz. Dent. J., 23(1): 2227.

Gulcin I. 2012. Antioxidant activity of food constituents: an overview. Arch. Toxicol., 86: 345-391.

Kiers CT, De Boer JL, Olthof R, Spek AL. 1976. "The crystal structure of a 2,2diphenyl-1-picrylhydrazyl (DPPH) modification". Acta Crystallographica Section B Structural Crystallography and Crystal Chemistry, 32(8): 2297.

Lin D. 2012. How do I store DPPH radical solution for the next use? And how long can I store it for? [http://www. researchgate.net/post/How_do_I_store_D PPH_radical_solution_for_the_next_use_ And_how_long_can_I_store_it_for]. [Accessed 20th February, 2014].

Marxen K, Vanselow KH, Lippemeier S, Hintze R, Ruser A, Hansen U-P. 2007. 
Determination of DPPH Radical Oxidation Caused by Methanolic Extracts of Some Microalgal Species by Linear Regression Analysis of Spectrophotometric Measurements. Sensors, 7: 2080-2095.

Meléndez NP, Nevárez-Moorillón V, Rodríguez-Herrera R, Espinoza JC, Aguilar CN. 2014. A microassay for quantification of 2,2-diphenyl-1picrylhydracyl (DPPH) free radical scavenging. Afr J. Biochem. Res., 8(1): 14-18.

Mensor LL, Menezes FS, Leitao GG, Reis AS, dos Santos TC, Coube CS, et al.. 2001. Screening of Brazilian plant extracts for antioxidant activity by the use of DPPH free radical method. Phytother. Res., 15: 127-130.

Molyneux P. 2004. The use of the stable free radical diphenylpicrylhydrazyl (DPPH) for estimating antioxidant activity. Songklanakarin J Sci Technol, 26: 211219.

Pisoschi AM, Negulescu GP. 2011. Methods for Total Antioxidant Activity Determination: A Review. Biochem \& Anal Biochem 1: 106.

Prior RL, Wu X, Schaich K. 2005. Standardized methods for the determination of antioxidant capacity and phenolics in foods and dietary supplements. J. Agri. Food Chem., 53: 4290-4302.

Rahman K. 2007. Studies on free radicals, antioxidants, and co-factors. Clinical Interventions in Aging., 2(2): 219-236.

Sahaa MR, Hasana SMR, Aktera R, Hossaina MM, Alamb MS, Alam MA, Mazumderc MEH. 2008. In vitro free radical scavenging activity of methanol extract of the leaves of Mimusops elengi linn. Bangl. J. Vet. Med., 6(2): 197-202.

Sharma OP, Bhat TK. 2009. DPPH antioxidant assay revisited. Food Chem., 113(4): 1202-1205.

Stasko A, Brezová V, Biskupic S, Misík V. 2007. The potential pitfalls of using 1,1diphenyl-2-picrylhydrazyl to characterize antioxidants in mixed water solvents. Free Radic. Res., 41(4): 379-390.

Teruaki F. 1981. "Magnetic Interaction in Solvent-free DPPH and DPPH-Solvent Complexes". Bulletin of the Chemical Society of Japan, 54(10): 3110.

Thaipong K, Boonprakob U, Crosby K, Cisneros-Zevallos L, Byrne DH. 2006. Comparison of ABTS, DPPH, FRAP, and ORAC assays for estimating antioxidant activity from guava fruit extracts. J. Food Composition \& Analysis, 19: 669-675. 